\title{
Article \\ The Serine Biosynthesis of Paenibacillus polymyxa WLY78 Is Regulated by the T-Box Riboswitch
}

\author{
Haowei Zhang, Qin Li, Yongbin Li and Sanfeng Chen *
}

check for updates

Citation: Zhang, H.; Li, Q.; Li, Y.; Chen, S. The Serine Biosynthesis of Paenibacillus polymyxa WLY78 Is Regulated by the T-Box Riboswitch. Int. J. Mol. Sci. 2021, 22, 3033. https://doi.org/10.3390/ ijms22063033

Academic Editor: Georg A. Sprenger

Received: 23 February 2021

Accepted: 15 March 2021

Published: 16 March 2021

Publisher's Note: MDPI stays neutral with regard to jurisdictional claims in published maps and institutional affiliations.

Copyright: (c) 2021 by the authors. Licensee MDPI, Basel, Switzerland. This article is an open access article distributed under the terms and conditions of the Creative Commons Attribution (CC BY) license (https:/ / creativecommons.org/licenses/by/ $4.0 /)$.
State Key Laboratory for Agrobiotechnology and College of Biological Sciences, China Agricultural University, Beijing 100094, China; zhanghw@cau.edu.cn (H.Z.); lqliqin1@126.com (Q.L.); ybli@cau.edu.cn (Y.L.)

* Correspondence: chensf@cau.edu.cn; Tel.: +86-10-62731551

\begin{abstract}
Serine is important for nearly all microorganisms in protein and downstream amino acids synthesis, however, the effect of serine on growth and nitrogen fixation was not completely clear in many bacteria, besides, the regulatory mode of serine remains to be fully established. In this study, we demonstrated that L-serine is essential for growth and nitrogen fixation of Paenibacillus polymyxa WLY78, but high concentrations of L-serine inhibit growth, nitrogenase activity, and nifH expression. Then, we revealed that expression of the ser $A$ whose gene product catalyzes the first reaction in the serine biosynthetic pathway is regulated by the T-box riboswitch regulatory system. The $508 \mathrm{bp}$ mRNA leader region upstream of the ser $A$ coding region contains a $280 \mathrm{bp}$ T-box riboswitch. The secondary structure of the T-box riboswitch with several conserved features: three stem-loop structures, a 14-bp T-box sequence, and an intrinsic transcriptional terminator, is predicted. Mutation and the transcriptional leader-lacZ fusions experiments revealed that the specifier codon of serine is AGC (complementary to the anticodon sequence of $\mathrm{tRNA}^{\mathrm{ser}}$ ). qRT-PCR showed that transcription of $\operatorname{ser} A$ is induced by serine starvation, whereas deletion of the specifier codon resulted in nearly no expression of ser $A$. Deletion of the terminator sequence or mutation of the continuous seven $\mathrm{T}$ following the terminator led to constitutive expression of $\operatorname{ser} A$. The data indicated that the T-box riboswitch, a noncoding RNA segment in the leader region, regulates expression of $\operatorname{ser} A$ by a transcription antitermination mechanism.
\end{abstract}

Keywords: T-box riboswitch; Paenibacillus polymyxa WLY78; serine; serA

\section{Introduction}

Riboswitches, one type of non-coding RNAs, are genetic regulation elements commonly located in the $5^{\prime}$-untranslated regions (5'-UTRs) of mRNAs [1-3]. Many bacteria use riboswitches to detect a variety of metabolites and ions to regulate gene expression. Riboswitches consist of two functional domains, the ligand-binding aptamer domain and the downstream adjoining expression platform $[4,5]$. The aptamer domain is able to bind a small molecule with high selectivity and affinity, such as amino acids, nucleobases, vitamin cofactors, and secondary messenger molecules [6-11]. The binding of a ligand to the aptamer domain will cause conformation changes that are transduced into the expression platform domain which finally results in expression regulation of downstream genes [4]. To date, more than 25 riboswitch classes that respond to various signals have been identified and characterized [12]. For example, the expression of methionine and cysteine biosynthesis genes is controlled by the S-box riboswitch in which S-adenosylmethionine (SAM) is the molecular effector sensed by the S-box leader RNAs during transcription [13,14].

The T-box riboswitches commonly modulate the expression of many genes encoding aminoacyl-tRNA synthetase, as well as genes encoding selected amino acid synthetase and transporter in Gram-positive bacteria [15-18]. A T-box RNA consists of a segment of leader RNA with conserved features. One feature includes a T-box sequence consisting of a conserved 14-nucleotide sequence (5'-AGGGUGGNACCGCG-3') and another feature includes an element (a $\mathrm{G}+\mathrm{C}$-rich helix followed by a run of $\mathrm{U}$ residues) that serves as an 
intrinsic transcriptional terminator [16,19-22]. The T-box sequence is predicted to form the $5^{\prime}$ side of an alternate, less stable antiterminator structure that competes with the formation of the more stable terminator helix [15]. In addition to the segments that can form the terminator/antiterminator elements, the major structures formed within the T-box RNA are designated stem I, stem II, the stem IIA/stem IIB pseudoknot, and stem III [19,23,24]. Stem I contains the specifier sequence (complementary to the anticodon sequence of tRNA) that selectively pairs with a cognate tRNA [25]. The specifier sequence binds charged tRNA or uncharged tRNA in response to amino acid starvation. Binding of a specific uncharged tRNA stabilizes the antiterminator, prevents the formation of the terminator helix, and thus promotes expression of the downstream coding sequence. Whereas, binding of charged tRNA promotes the formation of the terminator helix indirectly and thus represses expression of the downstream genes $[15,26]$.

The amino acid L-serine (Ser) is required for protein synthesis. Serine is also a chassis material for the biosynthesis of glycine, cysteine, and tryptophan. Glycine, in turn, is a precursor for purines and heme [27-33]. The first reaction in the serine biosynthetic pathway is the conversion of 3-phosphoglycerate to 3-phosphohydroxypyruvat catalyzed by 3-phosphoglycerate dehydrogenase encoded by the ser $A$ gene [13]. The regulation mechanism of ser $A$ in most members of the Firmicutes is unknown, although a T-box sequence is found in the serA regulatory region in Bacillus clausii, Bacillus halodurans, Clostridiium acetobutylicum, Clostridiium tetani, Clostridium kluyveri, and Clostridium novyi [19,34]. According to the RegPrecise database, in several Bacillus spp. (including B. subtilis) and other Firmicutes., ser $A$ is also regulated by the global transcriptional regulator CodY which is a sensor of nutrient availability [35], suggesting that regulation of serA is important to bridge the pathways between glycolysis and serine biosynthesis.

In this study, we examined the effects of L-serine on growth, nitrogenase activity, and nifH expression of P. polymyxa WLY78 which is a nitrogen-fixing bacterium and has great potential usage as a biofertilizer in agriculture. Then, we searched the genome sequence of the P. polymyxa WLY78 and found that a serA and a serC that are predicted to catalyze the first and the second reactions in the serine biosynthesis pathway are distributed separately. 5'-RACE (5'-Rapid Amplification of cDNA End) showed that the leader region upstream of the serA coding region is $508 \mathrm{bp}$ in length and there is a $280 \mathrm{bp}$ T-box region with several conserved sequences in the leader region. Alternation analysis of the three codons of serine revealed that the specifier codon is AGC. qRT-PCR analysis of the four mutants carrying the mutations in the T-box region demonstrated that the specifier codon and termination structure are essentially required for regulation of the $\operatorname{ser} A$ expression. Our study not only reveals the regulation mechanisms of serine biosynthesis in P. polymyxa WLY78, but also will provide assistance for understanding the relationship between amino acids and nitrogen fixation.

\section{Results}

2.1. Impacts of Serine Concentration on Growth, Nitrogenase Activity, and nifH Expression of $P$. polymyxa WLY78

To test whether L-serine could be used as the sole nitrogen source for the growth of $P$. polymyxa WLY78, 0-10 mM L-serine was supplemented in medium lacking nitrogen source. As shown in Figure 1, P. polymyxa WLY78 did not grow in medium without L-serine. It grew well in presence of L-serine and showed the best growth in the presence of $2 \mathrm{mM}$ L-serine (Figure 1), suggesting that L-serine can be used as the sole nitrogen source for the growth of P. polymyxa WLY78. 


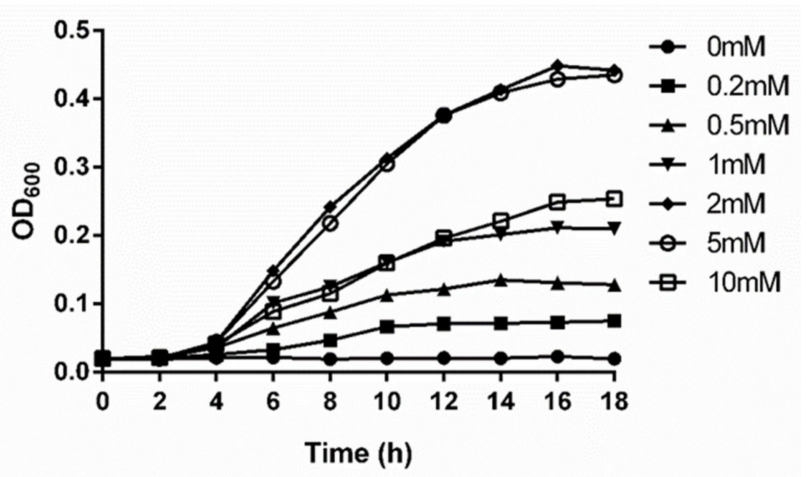

Figure 1. The growth rates of P. polymyxa WLY78 cultivated in minimal medium with L-serine as the sole nitrogen source. L-serine concentrations ranged from 0 to $10 \mathrm{mM}$. Results are representative of at least three independent experiments, mean values were calculated from three sets of independent experiments.

Impacts of serine concentration on nitrogenase activities and nifH expression of P. polymyxa WLY78 were here investigated. P. polymyxa WLY78 showed high nitrogenase activities when it was grown in nitrogen-limited medium containing $0-0.5 \mathrm{mM}$ of serine, but activities decreased as serine concentration increased (Figure 2A). qRT-PCR showed that the nifH of $P$. polymyxa WLY78 was transcribed in medium containing $0-0.5 \mathrm{mM} \mathrm{L-}$ serine, but it was not transcribed in medium containing $2 \mathrm{mM}$ L-serine or $5 \mathrm{mM}$ L-serine (Figure 2B), suggesting that $2 \mathrm{mM}$ and more than $2 \mathrm{mM}$ L-serine inhibited nif transcription. The data was in agreement with the nitrogenase activity observed above.

A

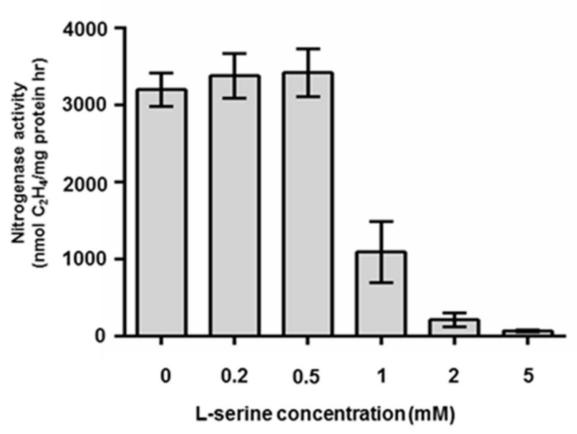

B

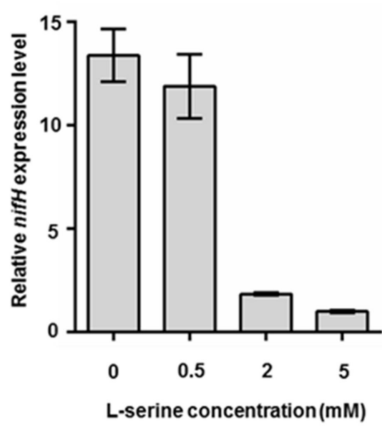

Figure 2. Nitrogenase activity and nifH expression of $P$. polymyxa WLY78 grown in different concentrations of serine. (A) The nitrogenase activity of P. polymyxa WLY78 grown in nitrogen-limited medium containing 0-5 mM L-serine. (B) The nifH expression level of P. polymyxa WLY78 grown in nitrogen-limited medium containing 0-5 mM L-serine determined by qRT-PCR. Results are representative of at least three independent experiments, mean values \pm SDs were calculated from three sets of independent experiments.

\subsection{The serA Gene Is Essential for Growth of P. polymyxa WLY78 in Absence of Serine}

We searched the genome of P. polymyxa WLY78 and found a serA gene was located between a resDE operon (coding for a two-component regulatory system) and a CBPB gene (coding for a CPBP family intramembrane metalloprotease). A serC gene is located elsewhere far from serA on the genome of P. polymyxa WLY78, but the serB gene is not found.

Here, the ser $A$ deletion mutant $(\triangle \operatorname{ser} A)$ of $P$. polymyxa WLY78 was constructed. In the minimal medium without serine, $P$. polymyxa WLY78 grew well, but the $\triangle$ ser $A$ mutant nearly could not grow. The $\Delta \operatorname{ser} A$ mutant grew well with the addition of serine in medium and grew best when serine concentration was $1 \mathrm{mM}$. The data suggested that $\operatorname{ser} A$ is essential for bacterial growth in the absence of serine (Figure 3 ). The growth of both the 
$\Delta$ serA mutant and P. polymyxa WLY78 decreased as serine concentration was more than $1 \mathrm{mM}$.

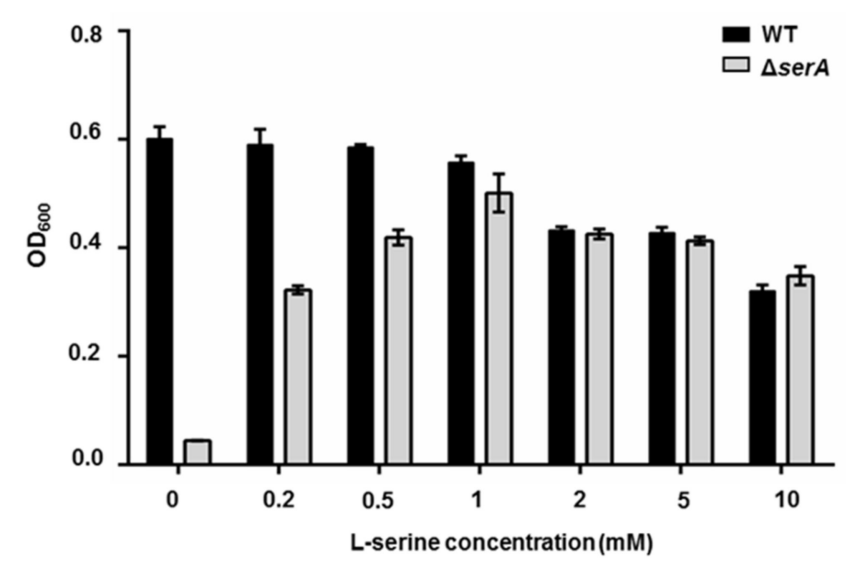

Figure 3. Comparison of the growth of P. polymyxa WLY78 and the $\Delta$ serA mutant in medium containing different concentrations of serine. The $\mathrm{OD}_{600}$ was measured at the stationary phase when growth reached maximum value. The medium contained $\mathrm{NH}_{4} \mathrm{NO}_{3}$ as the nitrogen source. Results are representative of at least three independent experiments, mean values \pm SDs were calculated from three sets of independent experiments.

\subsection{Characterization of the T-box Riboswitch of the serA Gene}

Here, the transcription start site (TSS) of the serA gene of P. polymyxa WLY78 was determined by using the $5^{\prime}$-RACE (Rapid Amplification of cDNA Ends) method. The TSS of the ser $A$ gene is located at -508 bp upstream of the translational start site (ATG). A putative promoter ( -35 region and -10 region) was identified in front of the TSS (Figure 4A). The data suggested that the mRNA leader region is $508 \mathrm{bp}$ in length. The Ser T-box riboswitch is $280 \mathrm{bp}$ in length from +1 (TSS) to +280 (end of a string of $\mathrm{U}$ residues behind the terminator) The conserved motifs: AG bulge, T-box sequence, and rho-independent transcriptional terminator (inverted repeat sequence followed by a string of $U$ residues in the RNA sequence), were identified in the Ser T-box riboswitch.

Reverse Transcription-PCR (RT-PCR) experiments using two pairs of primers (P1 and $\mathrm{P} 2)$ and (P1 and P3) were performed to determine that the leader region of the serA gene was co-transcribed with the serA coding region. The primers P1 and P2 were used to amplify a $252 \mathrm{bp}$ of a double cDNA fragment (from $+13 \mathrm{bp}$ to $+264 \mathrm{bp}$ relative to TSS) that includes T-box RNA. The primers P1 and P3 were designed to amplify a $686 \mathrm{bp}$ of double cDNA fragment from $+13 \mathrm{bp}$ to the 190th bp (relative to the translation start site ATG) in the coding region of ser $A$ that spans across leader sequence and coding region. The data indicated that T-box RNA in the leader RNA of the serA gene was co-transcribed with the serA coding region (Figure $4 \mathrm{~B}$ ). 
A

$-35$

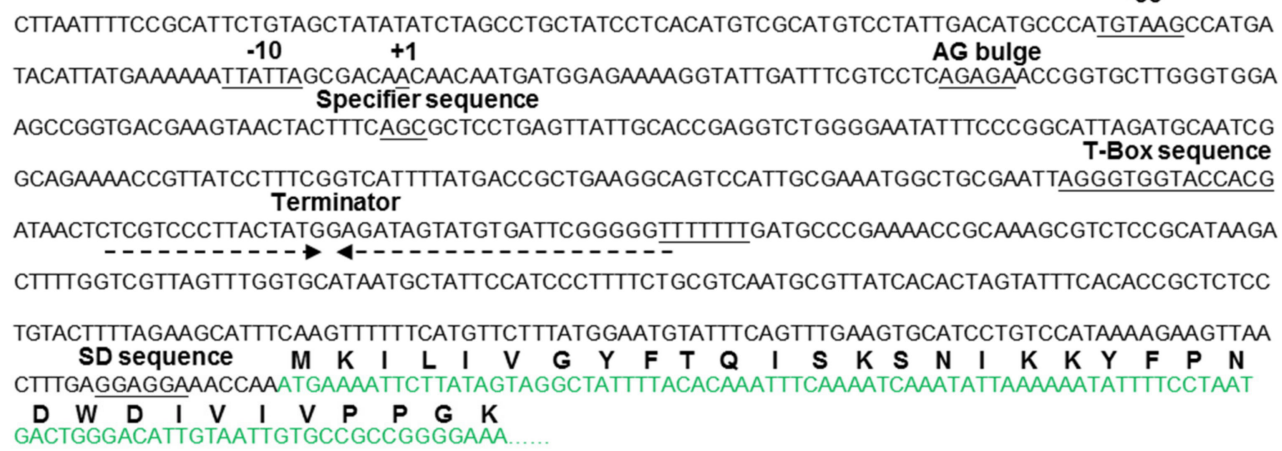

B

B
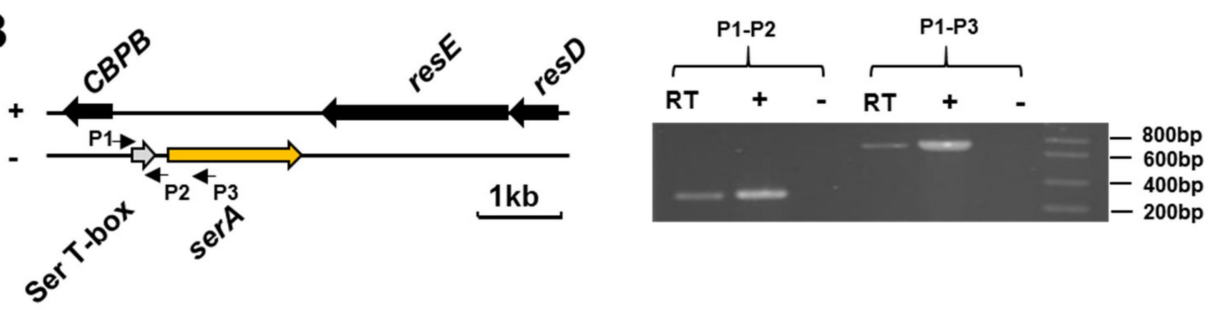

Figure 4. Characterization of the T-box region of the serA gene of P. polymyxa WLY78. (A) The leader sequence and some conserved features of the Ser T-box region. TSS site (+1), $-35 /-10$ region, AG bulge, T-box sequence, and terminator region are shown. (B) Identification of Ser T-box RNA by RT-PCR. The Ser T-box region is indicated by an arrow in grey color and serA gene in orange color. P1, P2, and P3 that represented by little arrows are primers for RT-PCR. A 252 bp fragment obtained by using P1 and P2 primers and a 686 bp fragment obtained by using P1 and P3 primers are shown on the agarose gel. RT, standard RT-PCR reaction; (-), negative control in which no reverse transcriptase was added to the RT reaction; (+), positive control in which genomic DNA was used as a template in the RT-PCR.

\subsection{The Secondary Structure of Ser T-box RNA}

Generally, the T-box RNA should consist of a segment of leader RNA with conserved features that allow recognition of and pairing with the specific charged $t R N A^{\text {Ser }}$ or uncharged tRNA. Here, the secondary structure of Ser T-box of P. polymyxa WLY78 was predicted by using RNA Folding Form software online (http:/ / unafold.rna.albany.edu/ ?q=mfold, accessed on 15 September 2020) [36] and the data from T-box Riboswitch Annotation Database (https: / / tbdb.io, accessed on 25 September 2020) [37]. Ser T-box RNA contains the segments that can form the terminator/antiterminator (Figure 5). In addition, the major structures formed within the T-box RNA include Stem I, Stem II, and Stem III preceding the terminator/antiterminator regions. A kink-turn motif is located at the bottom of Stem I, which modulates the angle of the backbone of the T-box. The specifier loop above the kink-turn motif is responsible for codon-anticodon interaction with seryltRNA, and the specifier sequence (AGC), the conserved sequence within the AG bulge (AGAGA) and Stem I terminal loop (GUUGGAA) is able to form a platform to interact with the D-/T-loop of tRNA elbow. Stem II comprises an S-turn motif and a terminal loop. However, Stem II A/B is not found in the 46-nucleotide region between Stem II and III. A 14-nucleotide T-box sequence (5'-AGGGUGGUACCACG-3') follows Stem III, and this sequence precedes an intrinsic transcription terminator helix in the leader region of the $\operatorname{ser} A$ gene, suggesting a common regulatory mechanism involving transcription attenuation. When intracellular serine concentration is too low, UGGU within the T-box sequence may pair with the acceptor arm of uncharged $t \mathrm{RNA}^{\text {Ser }}$ to form an antiterminator structure to derepress downstream ser $A$ expression. 
A

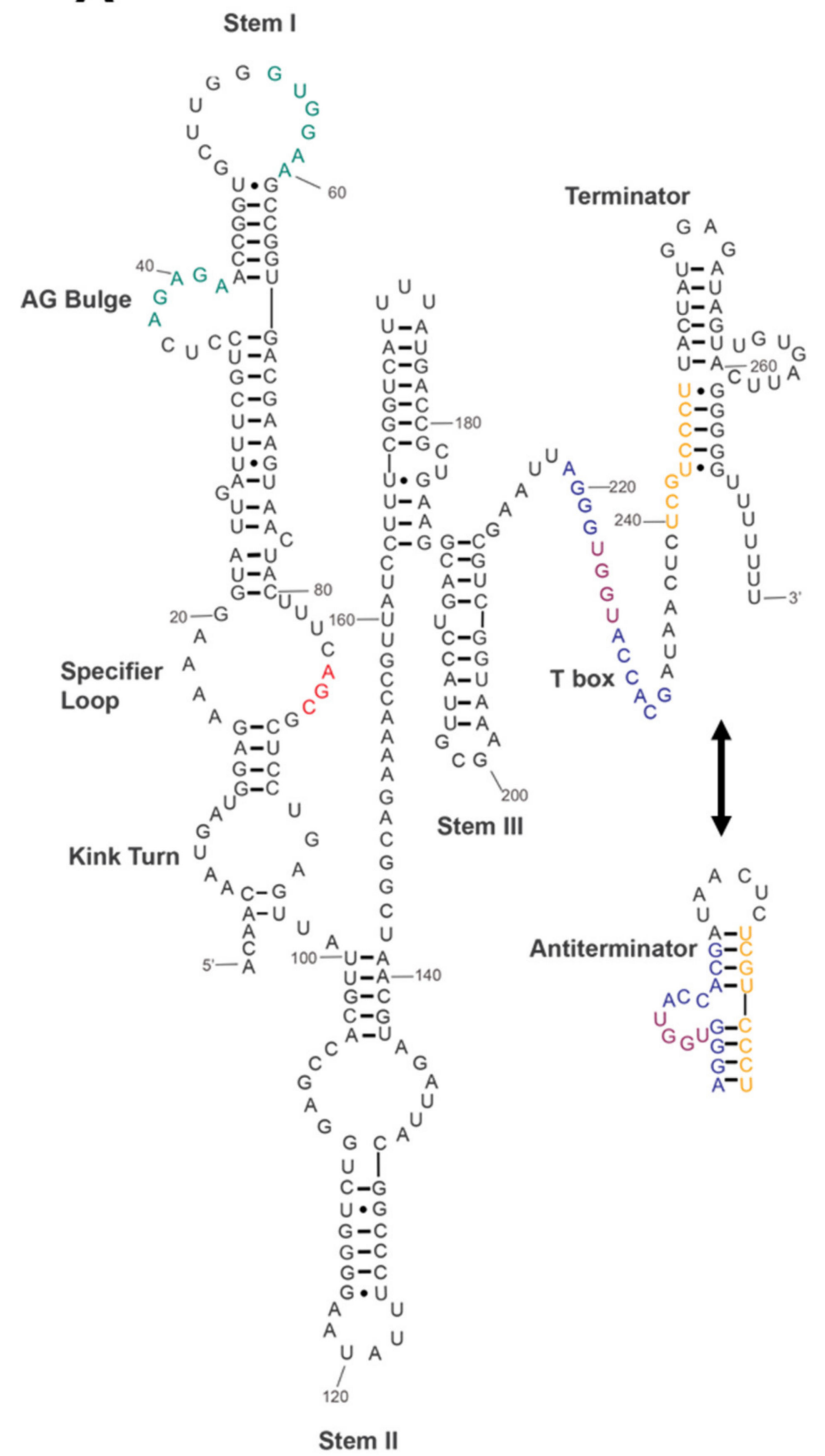

B

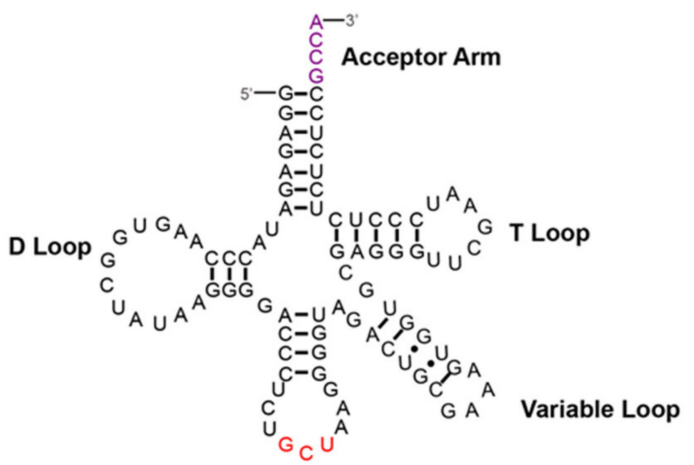

Anticodon Loop

Figure 5. The predicted secondary structures of Ser T-box riboswitch and $t R N A^{\text {Ser }}$. (A) The Ser T-box sequence is numbered from the transcriptional start site to the end of the transcriptional terminator region. Conserved sequence motifs are labeled in different colors. The specifier sequence (AGC residues complementary to the anticodon sequence of tRNA ${ }^{\text {Ser }}$ ) in the specifier loop is in red. The conserved AG bulge and terminal loop sequences of Stem I are shown in green. The T-box residues (AGGGUGGUACCACG) are shown in blue. The purple-labeled residues (UGGU) within the T-box sequence pair with the acceptor arm sequence of tRNA ${ }^{\text {Ser }}$. The orange-labeled residues (UCGUCCCU) interact with the T-box sequence to form an antiterminator structure. (B) Cloverleaf structure of tRNA ${ }^{\text {Ser }}$. Conserved structure motifs include D-loop, T-loop, Variable loop, and Acceptor arm. The anticodon sequence is shown in red. The sequence (purple) in the acceptor arm base-pair with the Ser T-box antiterminator bulge.

\subsection{Identification of the Specifier Codon for Ser in the T-box Riboswitch}

There are three predicted Ser codon sequences: AGC (from +85 to +87 bp relative to transcription start site), UCC (from $+90 \mathrm{bp}$ to $+92 \mathrm{bp}$ ), and AGU (from +95 bp to $+97 \mathrm{bp}$ ) in the upstream region of the 14-nucleotide T-box sequence (5'-AGGGUGGUACCACG-3'). The three Ser codon sequences AGC, UCC, and AGU were mutated to AGA (glutamate), ACC (histidine), and AGA (glutamate), respectively. A total of $606 \mathrm{bp}$, including a $188 \mathrm{bp}$ promoter region preceding the TSS and a $508 \mathrm{bp}$ of the leader sequence (containing the wild-type Ser codon sequence or the mutated codon sequence), was fused to the lac $Z$ coding region, and the four vectors were transformed into P. polymyxa WLY78, yielding PserA- 
lacZ, C87A-lacZ, T90A-lacZ, and T97A-lacZ mutants, respectively. The $\beta$-galactosidase activities of these mutants were determined when they were grown in medium containing $2 \mathrm{mM}$ L-serine or without L-serine. As shown in Figure 6, the WT strain had much higher $\beta$-galactosidase activity in medium without L-serine than in medium containing $2 \mathrm{mM}$ L-serine. As observed in PserA-lacZ, T90A-lacZ, and T97A-lacZ mutants had much higher $\beta$-galactosidase activity in medium without L-serine than in medium containing $2 \mathrm{mM}$ L-serine, indicating that mutation of UCC (from $+90 \mathrm{bp}$ to $+92 \mathrm{bp}$ ) or AGU (from $+95 \mathrm{bp}$ to $+97 \mathrm{bp}$ ) did not produce any impacts on regulation exhibited by serine. However, strain C87A-lacZ had only the basal $\beta$-galactosidase activity in the absence or in the presence of Lserine, suggesting that the mutation of AGC (from $+85 \mathrm{bp}$ to $+87 \mathrm{bp}$ relative to transcription start site) resulted in the loss of regulation by serine. These results indicated that Ser T-box was a bona fide serine T-box, and the specifier codon of Ser T-box was AGC residues (from +85 to +87 bp relative to transcription start site) that were complementary to the anticodon sequence of $\mathrm{tRNA} \mathrm{Aer}^{\mathrm{Ser}}$. The data suggested that a single codon in the leader region acts as a specifier sequence, controlling the amino acid response.

A

B $\beta$-galactosidase activity
(units/mg protein)

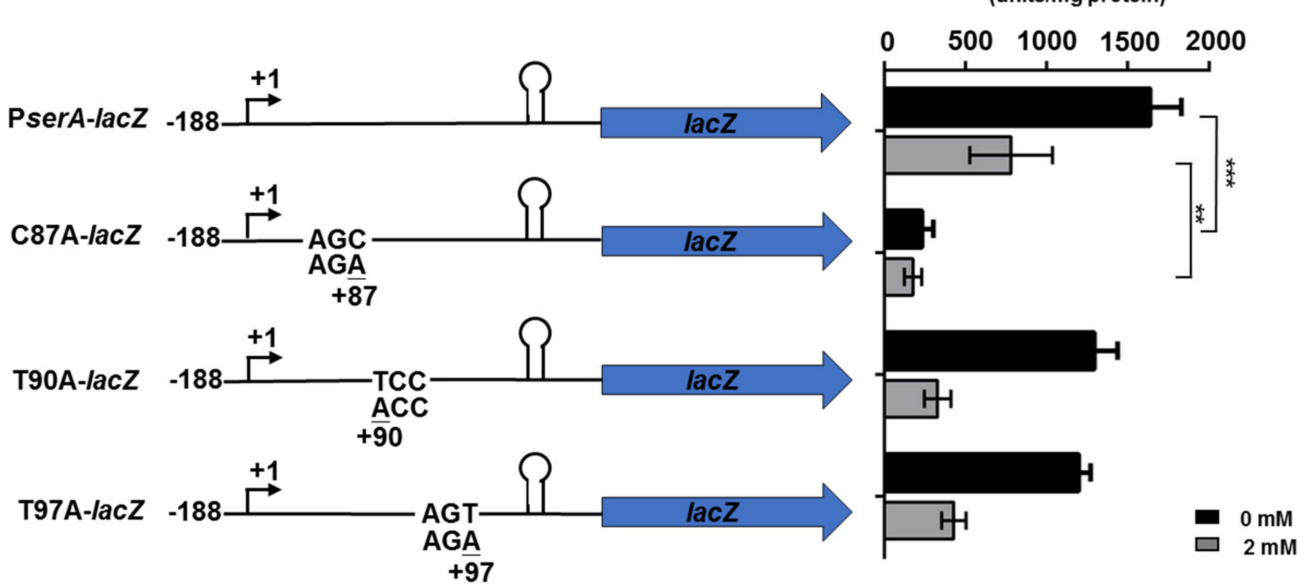

Figure 6. Scheme of mutation of specifier codon of serine and the $\beta$-galactosidase activities expressed from the leader-lac $Z$ fusion carrying wild-type Ser codon sequence or the mutated codon sequence. (A) Scheme of mutation of specifier codon of serine and the leader-lacZ fusion carrying wild-type Ser codon sequence or the mutated codon sequence. (B) The $\beta$-galactosidase activities of $P$. polymyxa strains grown in minimal medium containing 0 and $2 \mathrm{mM}$ L-serine. Results are representative of at least three independent experiments, mean values \pm SDs were calculated from three sets of independent experiments. ${ }^{* *} p<0.001 .{ }^{* *}$ for $p<0.01$.

\subsection{Mutations of the Conserved Motifs in T-box RNA Affect the serA Expression}

As described above, there are several conserved motifs in Ser T-box RNA of the serA gene, including Stem I, Stem II, Stem III, a 14-nucleotide T-box sequence, and terminator/antiterminator helixes. In order to investigate if these motifs are involved in the regulation of serA expression, four T-box mutants with the deletion of different lengths of the T-box segments on chromosome were constructed as described in the materials and methods section. As shown in Figure 7A, Ser T-box ${ }^{\Delta 216}$ was constructed by deleting a 216 bp fragment (from +13 to +228 relative to TSS), including the specific codon AGC for Ser (complementary to the anticodon sequence of tRNA ${ }^{\mathrm{ser}}$ ) and a 14-nucleotide T-box sequence. The Ser T-box ${ }^{\Delta 70}$ mutant had a deletion of a $70 \mathrm{bp}$ fragment (from +85 to +154 relative to TSS) including the specific codon AGC, but it still contained a 14-nucleotide T-box sequence. The Ser T-box ${ }^{\Delta 70-B a m H I}$ mutant was constructed by changing the sequence TTTTTTT following the terminator to TGGATCC in the Ser T-box ${ }^{\Delta 70}$ mutant, which was performed by using a restriction site of BamHI (GGATCC) to replace TTTTTT. The Ser T-box ${ }^{\Delta 280}$ mutant deleted the $280 \mathrm{bp}$ full-length of the Ser T-box riboswitch (from +1 to 
+280 bp relative to TSS), including TSS, a 14-nucleotide T-box sequence, and the putative terminator sequence.

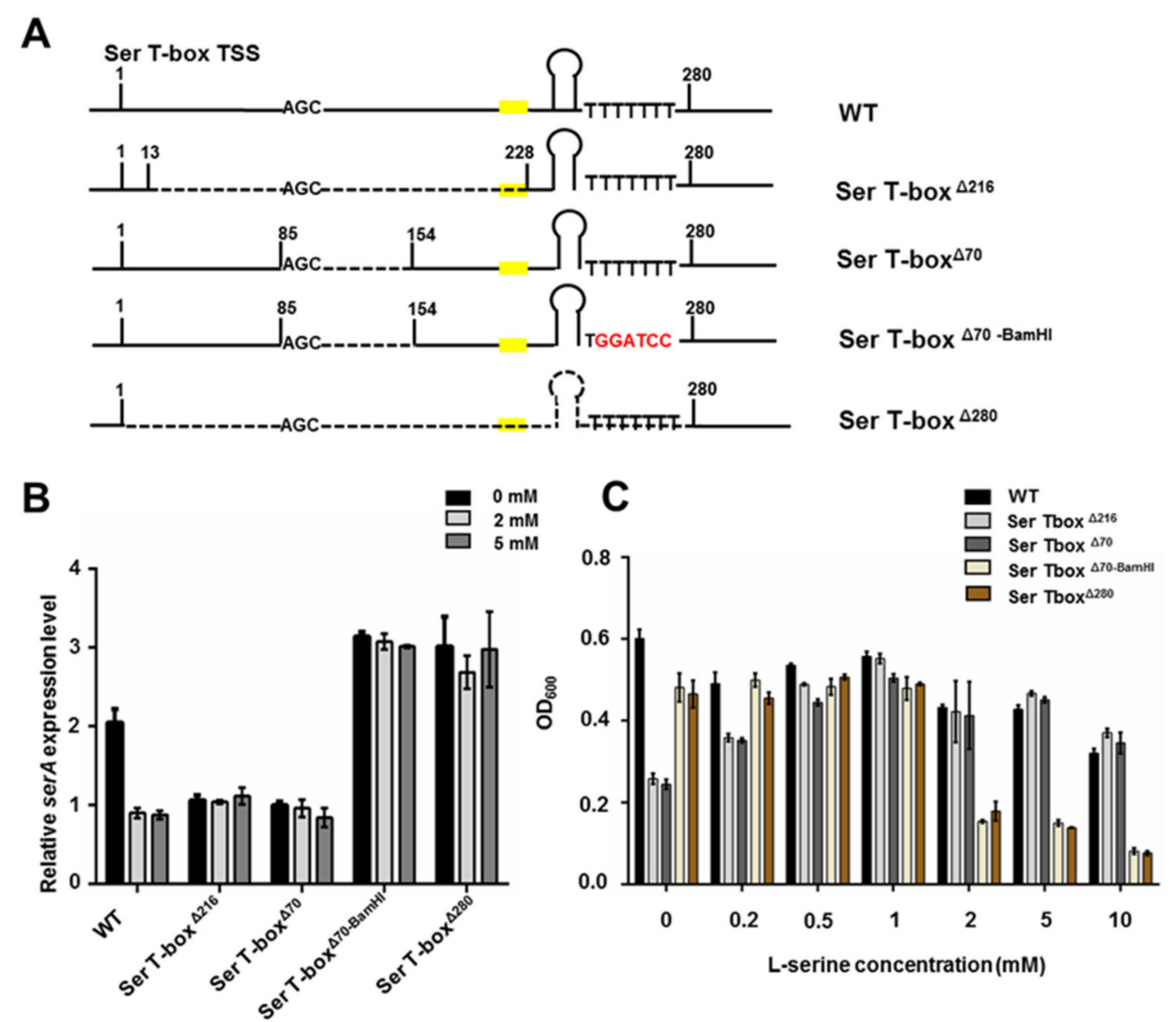

Figure 7. Scheme of mutation of the Ser T-box and the effects on growth and serA expression. (A) A scheme of mutation of the Ser T-box. The Ser T-box riboswitch is $280 \mathrm{bp}$ in length. The number 1 is the start site of transcription and is also the start site of the Ser T-box riboswitch. The number represents the position of Ser T-box, the dotted line represents the deletion region and red-labeled nucleotides represent the BamHI mutation region. AGC represented the specifier codon and the yellow box represented the position of the 14-bp T-box sequence. (B) qRT-PCR analysis of the serA expression level of WT, Ser T-box ${ }^{\Delta 70}$, and Ser T-box ${ }^{\Delta 70-B a m H I}$ strains grown on nitrogen-limited medium with 0 , 2, and $5 \mathrm{mM}$ concentrations of L-serine. (C) The growth of WT (P. polymyxa WLY78) and mutants grown under minimal medium containing $0-5 \mathrm{mM} \mathrm{L}$-serine, and the $\mathrm{OD}_{600}$ was measured after $16 \mathrm{~h}$ growth within stationary phases. Results are representative of at least three independent experiments, mean values \pm SDs were calculated from three sets of independent experiments.

qRT-PCR analysis revealed that the transcript level of the ser $A$ gene of $P$. polymyxa WLY78 was much higher in minimal medium without serine than in medium containing 2 or $5 \mathrm{mM}$ serine (Figure 7B), indicating that serA expression was inhibited by $2 \mathrm{mM}$ L-serine. However, the expression levels of the ser $A$ gene in both Ser T-box ${ }^{\Delta 216}$ and Ser T-box ${ }^{\Delta 70}$ mutants grown in medium with serine or without serine were continuously low. The transcript levels of both mutants were close to those of the P. polymyxa WLY78 in medium containing 2 and $5 \mathrm{mM}$ L-serine. A common feature of Ser T-box ${ }^{\Delta 216}$ and Ser T-box ${ }^{\Delta 70}$ mutants is the absence of the specific codon AGC of Ser (complementary to the anticodon sequence of $\mathrm{RNA}^{\mathrm{ser}}$ ). The data suggest that the absence of the specific codon AGC resulted in inhibition of the serA expression. Whereas the transcripts of the serA in both Ser T-box ${ }^{\Delta 70-B a m H I}$ and Ser T-box ${ }^{\Delta 280}$ mutants were at similarly high levels whether there was serine or not. And the transcripts of $\operatorname{ser} A$ in both mutants under the two conditions were much higher than that of P. polymyxa WLY78 in medium without serine. 
The data suggest that expression of $\operatorname{ser} A$ in the two mutants was not regulated by the T-box riboswitch according to serine concentration. A common feature of the two mutants is that the terminator structure is destroyed. Thus, deletion of the terminator sequence or mutation of the continuous $7 \mathrm{U}$ following the terminator sequence in the two mutants led to transcription through the serA coding region.

Effects of serine on the growth of these mutants and P. polymyxa WLY78 were determined (Figure 7C). P. polymyxa WLY78 grew well in the minimal medium without serine, suggesting that $\operatorname{ser} A$ can synthesize and provide serine for bacterial growth. However, the growth of P. polymyxa WLY78 decreased as the serine concentration increased, suggesting that a high concentration of serine inhibited growth and is consistent with the transcription results obtained by qRT-PCR. In contrast, the growth of Ser T-box ${ }^{\Delta 216}$ and Ser T-box ${ }^{\Delta 70}$ mutants were obviously lower than that of the wild-type P. polymyxa WLY78 in the medium without serine, suggesting synthesis of serine is inhibited and is consistent with the transcription results obtained by qRT-PCR. The growth of both Ser T-box ${ }^{\Delta 216}$ and Ser T-box ${ }^{\Delta 70}$ mutants were greatly recovered with the increasing of L-serine concentration, and the highest growth was observed in the presence of $1 \mathrm{mM}$ L-serine and then decreased when L-serine was more than $1 \mathrm{mM}$. Notably, the growth of both Ser T-box ${ }^{\Delta 70-B a m H I}$ and Ser T-box ${ }^{\Delta 280}$ mutants was nearly the same high level in the range of 0-1 mM L-serine. However, the growth of both Ser T-box ${ }^{\Delta 70-B a m H I}$ and Ser T-box ${ }^{\Delta 280}$ mutants was significantly decreased and was much lower than those of the wild-type P. polymyxa WLY78 and both Ser T-box ${ }^{\Delta 216}$ and Ser T-box ${ }^{\Delta 70}$ mutants when L-serine concentration is more than $2 \mathrm{mM}$. The data indicate that the growth of both Ser T-box ${ }^{\Delta 70-\mathrm{BamHI}}$ and Ser T-box ${ }^{\Delta 280}$ mutants was more inhibited by the intracellular serine than other strains. The results are in agreement with the fact that $\operatorname{ser} A$ was constitutively expressed at a high level in both Ser T-box ${ }^{\Delta 216}$ and Ser T-box ${ }^{\Delta 70}$ mutants and thus these mutants had a higher amount of the intracellular serine than the wild-type P. polymyxa WLY78 and both Ser T-box ${ }^{\Delta 216}$ and Ser T-box ${ }^{\Delta 70}$ mutants did.

\section{Discussion}

In this study, the effects of L-serine on growth and nitrogen fixation of $P$. polymyxa WLY78 were studied. We found that L-serine can be used as the sole nitrogen source for the growth of P. polymyxa WLY78. This bacterium grew well in the presence of $10 \mathrm{mM}$ L-serine, but the best growth was observed in the presence of $2 \mathrm{mM} \mathrm{L}$-serine, which indicated that too much L-serine inhibited growth. A previous study showed that L-serine would inhibit the growth of E. coli cells cultured in minimal medium with some certain carbohydrate as the sole carbon source including glucose by inhibiting homoserine dehydrogenase [33]. In B. subtilis, over $1 \mathrm{mM}$ of serine inhibits the growth of cells cultured in minimal medium, while the addition of serine to LB medium does not show any inhibition. Moreover, the addition of threonine partially overcomes serine toxicity, suggesting that the serine toxicity is due to the repression of threonine biosynthesis [38]. It might be the same situation in P. polymyxa WLY78.

The nitrogenase activity and nifH transcription were inhibited by more than $1 \mathrm{mM} \mathrm{L-}$ serine, which was in agreement with that L-serine could be used as the sole nitrogen source. When L-serine was added, the intracellular nitrogen pool elevated and the expression of nitrogen fixation genes was inhibited. Previous studies showed that the effects of amino acids on growth and nitrogen fixation varied greatly among the different Azospirillum species. A. brasilense grew poorly or not at all on serine as the sole nitrogen and carbon sources, and its nitrogenase activity was inhibited only slightly by even $10 \mathrm{mM}$ serine. In contrast, A. lipoferum and A. amazonense grew very well on serine as the sole nitrogen and carbon sources, and their nitrogenase activities were severely inhibited by the serine [39]. These results suggested that serine would not inhibit nitrogenase activity when it could not be used as nitrogen source, otherwise, the inhibition on nitrogenase activity existed. The different effects of serine on growth and nitrogen fixation may be due to different regulation mechanisms used by various organisms. 
Meanwhile, the lack of serine also inhibits growth and nitrogenase activity, especially for Ser T-box ${ }^{\Delta 70}$ and Ser T-box ${ }^{\Delta 70-B a m H I}$ mutants, the growth and nitrogenase activities of which decreased obviously without serine addition. P. polymyxa WLY78 has a nif gene cluster comprising nine genes (nifB, nifH, nifD, nifK, nifE, nifN, nifX, hes $A$, and nifV) encoding nitrogenase [40]. The serine and two downstream amino acids glycine and cysteine in the compositions of the proteins encoded by the nine genes accounted for $6.04 \%, 8.93 \%$, and $1.93 \%$, respectively. As for all proteins of $P$. polymyxa WLY78, the three amino acids accounted for $6.36 \%, 7.24 \%$, and $0.77 \%$, respectively, which means more glycine and cysteine demand of nitrogenase compared with the average level, and the two amino acids are synthesized from serine, though the proportion of serine of nine nitrogenase is a little lower than average level (Figure S1). Furthermore, the transcript levels of $P$. polymyxa $\operatorname{ser} A$ were much higher under nitrogen fixation conditions than in non-nitrogen fixation conditions (Figure S2), suggesting that more serine is synthesized under nitrogen fixation conditions than in non-nitrogen fixation conditions. One possible reason for nitrogenase activities reduction of Ser T-box ${ }^{\Delta 70}$ and Ser T-box ${ }^{\Delta 70-B a m H I}$ mutants is that the intracellular serine of these two mutants could not meet the demand of the nitrogen fixation process.

Then, we investigated the regulation mechanism of the $\operatorname{ser} A$ expression. A long (508 bp) leader sequence upstream of the ser $A$ coding region is identified. A T-box riboswitch with several conserved features: a single specifier codon for serine, three stemloop structures, a 14 bp sequence (the T-box), and an intrinsic transcriptional terminator is found in the long leader region. There are three predicted serine codon sequences: AGC, AGU, and ACC in the leader region. Alternation of each of the three serine codons showed that only the single codon AGC (from +85 to +87 bp relative to TSS) is the specifier codon for serine, consistent with the report that there is only a single specifier sequence complementary to tRNA in the aminoacyl-tRNA synthetase genes of B. subtilis [20]. It is predicted that the specifier codon for B. clausii and B. halodurans is Ser (AGC), while for Clostridium acetobutylicum and Clostridium tetani is Ser (UCC) [19], and the divergence of specifier codons for different microorganisms is to be researched.

Further, qRT-PCR showed that transcription of the ser $A$ in the wild-type P. polymyxa WLY78 was induced by serine starvation, whereas deletion of the specifier codon (AGC) resulted in nearly no $\operatorname{ser} A$ expression in the presence or absence of serine, suggesting that the specifier codon is essential for the ser $A$ expression. Deletion of the terminator sequence or the continuous TTTTTTT following the terminator structure led to constitutive expression of $\operatorname{ser} A$, suggesting that repression exhibited by the terminator is relieved. The data are consistent with the T-box riboswitch regulation system which forms the terminator or antiterminator depending on the aminoacylation state of the bound tRNA in response to amino acid starvation and to control gene expression. Also, the predicated structure of the T-box riboswitch in the leader region of the serA in P. polymyxa WLY78 has the conserved motifs as found in those of the aminoacyl-tRNA synthetase genes regulated by the T-box mechanism. Thus, our study revealed that the serA in P. polymyxa WLY78 is regulated by the T-box riboswitch control system in which a tRNA is an effector to modulate gene expression [16]. The predicted secondary structure of the Ser T-box riboswitch (Figure 5) is based on the online database and the published T-box structures. Although structures of Stem I and the terminator region are well-matched, some details still need to be improved on the basis of future experimental evidence.

In addition, we found that a serC is located separately from serA in P. polymyxa WLY78, but there is no T-box region upstream of the serC coding region. However, sequence analysis suggests that the serC gene in Clostridium thermocellum and Desulfitobacterium hafniense is regulated by a Ser (UCC) T-box RNA [19]. The variations in regulation mechanisms of amino acid synthesis among different organisms reflect that microorganisms take different strategies to control gene expression to adapt to the changing environments. Moreover, serS encoding Seryl-tRNA synthetase is a common member of Ser T-box regulon in many Firmicutes including B. subtilis and Paenibacillus species [34]. A serB gene has not been identified in many Firmicutes including all Paenibacillus species for a long time. A recent 
study has revealed that $y s a A$ encoding haloalkanoate dehalogenase may be the equivalent of serB in B. subtilis. The B. subtilis YsaA showed phosphatase activity against phosphoserine, phosphothreonine, phosphoethanolamine, and histidinol phosphate [41]. We have used the B. subtilis ysaA to search the genome of P. polymyxa WLY78 and found that there is a $y s a A$ gene in this bacterium.

According to our results, we proposed a regulatory model of L-serine biosynthesis in P. polymyxa WLY78 by the Ser T-box riboswitch (Figure 8). When L-serine is limited, the amount of uncharged serine-tRNA would increase and it pairs with the specifier codons in the T-box region to form an antiterminator, then the ser $A$ expression is switched on, and eventually, L-serine is synthesized. On the contrary, when intracellular L-serine is in excess, the charged tRNA could not pair with the $3^{\prime}$ side of the terminator region, and then the $\operatorname{ser} A$ expression was shifted to the switch-off state and L-serine biosynthesis was reduced to a relatively low level.

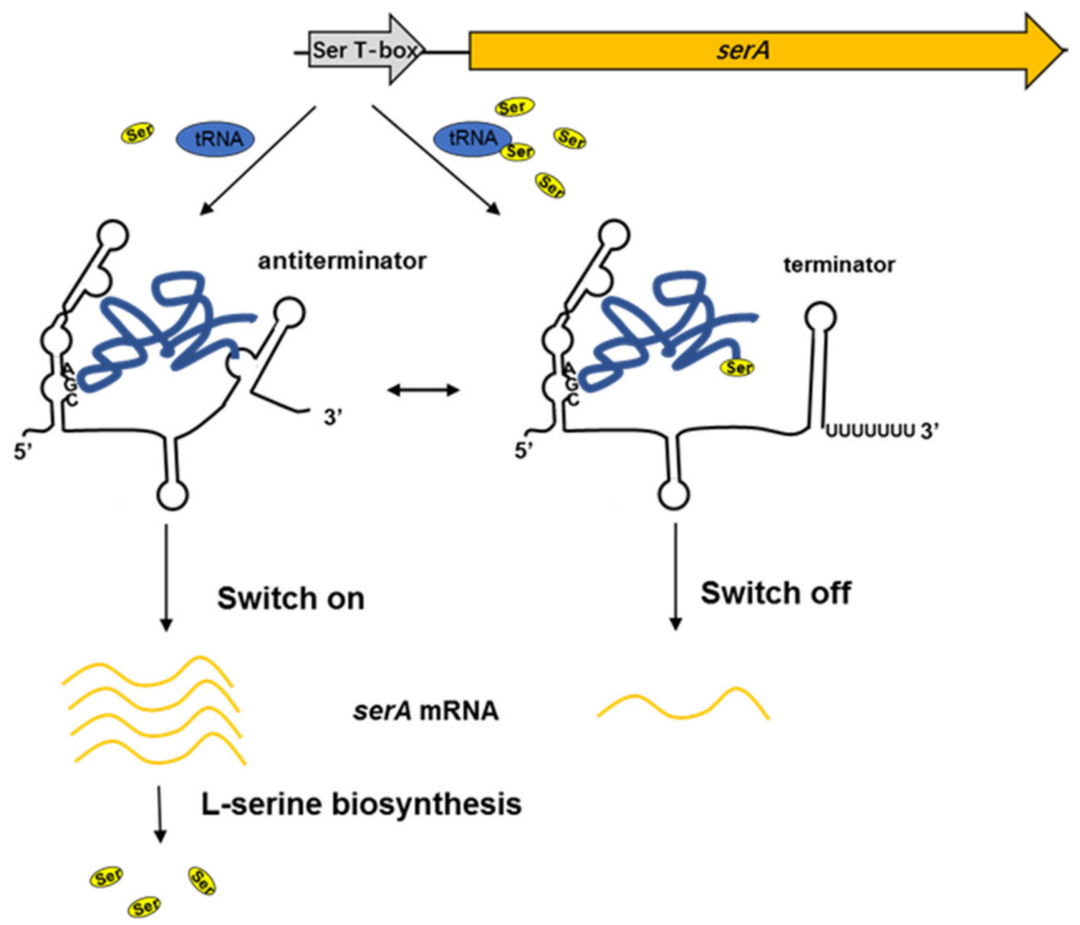

Figure 8. Regulatory model of the Ser T-box riboswitch involved in L-serine biosynthesis in P. polymyxa WLY78. In serine starvation, uncharged serine-tRNA pairs with the UGGU bulge within the T-box sequence to form an antiterminator structure, then ser $A$ expression is switched on. In serine abundance, the charged tRNA can not pair with the $3^{\prime}$ side of the intrinsic terminator region and the ser $A$ expression is switched off.

\section{Materials and Methods}

\subsection{Bacteria Strains, Plasmids, and Growth Conditions}

The bacterial strains and plasmids used in this study are shown in Supplementary Table S1. P. polymyxa strains were grown in LD medium (per liter contains: $5 \mathrm{~g} \mathrm{NaCl}, 5 \mathrm{~g}$ yeast extract, and $10 \mathrm{~g}$ tryptone) at $30^{\circ} \mathrm{C}$. For nitrogenase activity assays, P. polymyxa strains were grown in a nitrogen-limited medium under anaerobic conditions. Nitrogen-limited medium used in this study contained $10.4 \mathrm{~g} / \mathrm{L}$ of $\mathrm{Na}_{2} \mathrm{HPO} 4,3.4 \mathrm{~g} / \mathrm{L}$ of $\mathrm{KH}_{2} \mathrm{PO}_{4}, 26 \mathrm{mg} / \mathrm{L}$ of $\mathrm{CaCl}_{2} \cdot 2 \mathrm{H}_{2} \mathrm{O}, 30 \mathrm{mg} / \mathrm{L}$ of $\mathrm{MgSO}_{4}, 0.3 \mathrm{mg} / \mathrm{L}$ of $\mathrm{MnSO}_{4}, 36 \mathrm{mg} / \mathrm{L}$ of ferric citrate, $7.6 \mathrm{mg}$ $\mathrm{Na}_{2} \mathrm{MoO}_{4} \cdot 2 \mathrm{H}_{2} \mathrm{O}, 10 \mathrm{mg} / \mathrm{L}$ of p-aminobenzoic acid, $5 \mathrm{mg} / \mathrm{L}$ of biotin, and $2 \%(w / v)$ glucose with $2 \mathrm{mM}$ glutamate as the nitrogen source. To measure the growth, strains were grown in a mineral medium that contained $0.5 \mathrm{~g} / \mathrm{L} \mathrm{KH}_{2} \mathrm{PO}_{4}, 1.5 \mathrm{~g} / \mathrm{L} \mathrm{Na}_{2} \mathrm{HPO}_{4}, 1 \mathrm{~g} / \mathrm{L} \mathrm{NaCl}$, $0.2 \mathrm{~g} / \mathrm{L} \mathrm{MgSO}_{4} \cdot 7 \mathrm{H}_{2} \mathrm{O}, 5 \mathrm{~g} / \mathrm{L}$ glucose, and $1 \mathrm{~g} / \mathrm{L} \mathrm{NH}_{4} \mathrm{NO}_{3}$, and different concentrations of L-serine was added in some experiments. When serine was the sole nitrogen source, 
$\mathrm{NH}_{4} \mathrm{NO}_{3}$ was removed. Escherichia coli strains JM109 and DH5 $\alpha$ were used as routine cloning hosts. The thermo-sensitive vector pRN5101 was used as a gene cloning vector for gene nutation. The shuttle vector $\mathrm{pHY300PLK}$ that can be replicated in P. polymyxa strains and $E$. coli was used in the construction of $l a c Z$ fusion. When appropriate, antibiotics were added in the following concentrations: $100 \mu \mathrm{g} / \mathrm{mL}$ ampicillin, $5 \mu \mathrm{g} / \mathrm{mL}$ erythromycin, and $12.5 \mu \mathrm{g} / \mathrm{mL}$ tetracycline.

\subsection{Construction of Ser T-box ${ }^{\Delta 216}$, Ser T-box $\Delta^{\Delta 70}$, Ser T-box ${ }^{\Delta 280}$, and $\Delta$ serA Strains}

The in-frame-deletion mutant $(\Delta \operatorname{ser} A)$ of the ser $A$ gene in $P$. polymyxa was constructed. Also, the three mutants (Ser T-box ${ }^{\Delta 216}$, Ser T-box ${ }^{\Delta 70}$, Ser T-box ${ }^{\Delta 280}$ ) with different length deletion in the leader region of the $\operatorname{ser} A$ gene were constructed by using a homologous recombination method, respectively. For doing this, the upstream fragment $(\sim 1 \mathrm{~kb})$ and downstream fragment $(\sim 1 \mathrm{~kb})$ flanking the target sequence of Ser T-box and $\operatorname{ser} A$ were amplified by PCR using Phanta ${ }^{\circledR}$ Max Super-Fidelity DNA Polymerase (Vazyme Biotech Co., Ltd., Nanjing, China), respectively. The two fragments were then fused with the HindIII/BamHI digested pRN5101 vector using Gibson assembly master mix (New England Biolabs, USA), generating four recombinant plasmids: pRDSer T-box ${ }^{\Delta 216}$, pRDSer T-box ${ }^{\Delta 70}$, pRDSer Tbox $^{\Delta 280}$, and pRDser $A$. The four recombinant plasmids were individually transformed into P. polymyxa WLY78 as described by Wang et al. [40]. Then, the single crossover transformants were selected for erythromycin resistance $\left(\mathrm{Em}^{\mathrm{r}}\right)$. Subsequently, the double-crossover transformants were selected from the initial erythromycin transformants after several rounds of nonselective growth at $39^{\circ} \mathrm{C}$ and confirmed by PCR amplification using corresponding primers and Green Taq Mix (Vazyme Biotech Co., Ltd., Nanjing, China). The primers used here are listed in Supplementary Table S2.

\subsection{Construction of Ser T-box $x^{\Delta 70-B a m H I}$ Strain}

The mutant Ser T-box ${ }^{\Delta 70-B a m H I}$ was constructed in the background of the Ser T-box ${ }^{\Delta 70}$ mutant described above. The final 6T of the continuous 7T sequence (TTTTTT) in the leader region of the ser $A$ gene were replaced by a restriction site of BamHI (GGATCC) by primer design, the upstream fragment $(\sim 1 \mathrm{~kb})$ and downstream fragment $(\sim 1 \mathrm{~kb})$ flanking the region containing the continuous $\mathrm{T}$ sequences were amplified by PCR from genome DNA of Ser T-box ${ }^{\Delta 70}$. The two fragments were then fused to the HindIII/BamHI digested pRN5101 vector using Gibson assembly master mix, generating the recombinant plasmid pRUBamHI. The recombinant plasmid was transformed into the Ser T-box ${ }^{\Delta 70}$ mutant. The single-crossover transformants were selected for erythromycin resistance $\left(E \mathrm{~m}^{\mathrm{r}}\right)$. Subsequently, the double-crossover transformants were selected from the initial Erythromycin resistance transformants after several rounds of nonselective growth at $39{ }^{\circ} \mathrm{C}$. Then PCR amplification and subsequent digestion with BamHI were used to confirm the mutants. The primers used here are listed in Supplementary Table S2.

\subsection{Construction of Promoters-lacZ Fusion}

A total of $696 \mathrm{bp}$ fragments, including a $188 \mathrm{bp}$ promoter region preceding the TSS (transcription start site) and a $508 \mathrm{bp}$ DNA fragment preceding the of ATG (translation start site) was amplified from the genomic DNA of P. polymyxa WLY78 using primers Ser TboxpU-f and Ser T-boxp-r to construct PSer-lacZ. The lacZ coding region was amplified from the plasmid pPR9TT with primers lacZ-f and lacZ-r. The site mutation of specific codon was based on PSerA-lacZ using primers of MutC87A-f/MutC87A-r, MutT90A-f/MutT90A-r, and MutT97A-f/MutT90A-r by PCR, respectively. The PCR product was digested by DpnI then transformed to JM109 competent cells to select positive mutation transformants by sequencing. The successful site mutation fragment was PCR amplified and assembled to pHY300PLK and then transformed into P. polymyxa WLY78. 


\subsection{RNA Preparation, RT-PCR, and qRT-PCR Analysis}

The leader region was confirmed by reverse transcription PCR (RT-PCR), and transcription levels of genes were confirmed by quantitative real-time PCR (qRT-PCR). For corresponding experiments, $50 \mathrm{~mL}$ of cultures were harvested at $4{ }^{\circ} \mathrm{C}$ and rapidly frozen under liquid nitrogen. Total RNAs were extracted with RNAiso Plus (Takara, Japan) according to the manufacturer's protocol. Synthesis of cDNA was performed using PrimeScript RT reagent Kit with gDNA Eraser (Takara, Japan). For RT-PCR $0.5 \mu \mathrm{g}$ cDNA was used. qRT-PCR was performed on Applied Biosystems 7500 Real-Time System with the following program: $95^{\circ} \mathrm{C}$ for $15 \mathrm{~min}, 1$ cycle; $95^{\circ} \mathrm{C}$ for $10 \mathrm{~s}$, and $65^{\circ} \mathrm{C}$ for $30 \mathrm{~s}, 40$ cycles. The relative expression level was calculated using the $\Delta \Delta \mathrm{Ct}$ method, each experiment was performed in triplicate. Primers used for qRT-PCR are listed in Supplementary Table S2.

\subsection{Acetylene Reduction Assays of Nitrogenase Activity}

Acetylene reduction assays were performed as described previously to measure nitrogenase activity [40]. P. polymyxa WLY78 and its mutant strains were grown in $5 \mathrm{~mL}$ of LD medium overnight. The cultures were collected by centrifugation, washed three times with sterilized water, and then resuspended in a nitrogen-limited medium containing $2 \mathrm{mM}$ glutamate as a nitrogen source to a final $\mathrm{OD}_{600}$ of $0.2-0.4$. Then, $4 \mathrm{~mL}$ of the culture was transferred to a $25-\mathrm{mL}$ test tube and the test tube was sealed with a rubber stopper, L-serine was added to proper concentrations at the same time for special experiments. The headspace in the tube was then evacuated and replaced with argon gas. Then, approximately $2 \mathrm{~mL}$ of $\mathrm{C}_{2} \mathrm{H}_{2}$ (10\% of the headspace volume) was injected into the test tubes. After incubating the cultures at $30^{\circ} \mathrm{C}$ for the corresponding time, a $100 \mu \mathrm{L}$ gas sample was taken out and injected into gas chromatography to quantify ethylene $\left(\mathrm{C}_{2} \mathrm{H}_{4}\right)$ production. The nitrogenase activity was expressed in $\mathrm{nmol}_{2} \mathrm{H}_{4} / \mathrm{mg}$ protein $/ \mathrm{hr}$. All treatments were in three replicates and all the experiments were repeated three or more times.

\subsection{Identification of Transcription Start Site}

The $5^{\prime}$-RACE method was used to determine the transcription start site (TSS) using the SMARTer RACE cDNA Amplification Kit (Clontech, Japan). Gene-specific primers are listed in Supplementary Table S2. The PCR product was cloned into the $\mathrm{PGEM}^{\circledR}$-T vector (Promega, 2800 Woods Hollow Road, Madison, WI, USA) after adding A tail by taq DNA polymerase (Takara, Japan) and then sequenced.

Supplementary Materials: The following are available online at https:/ / www.mdpi.com/1422-006 $7 / 22 / 6 / 3033 /$ s1.

Author Contributions: Conceptualization, S.C.; Methodology, H.Z., Q.L., and Y.L.; Formal analysis: H.Z. and S.C.; Investigation: H.Z.; Writing-original draft preparation, H.Z. and S.C.; Writingreview \& editing, S.C.; Project administration: S.C.; Funding acquisition: S.C. All authors have read and agreed to the published version of the manuscript.

Funding: This work was supported by the National Key Research and Development Program of China (No. 2019YFA0904700).

Institutional Review Board Statement: Not applicable.

Informed Consent Statement: Not applicable.

Data Availability Statement: Not applicable.

Conflicts of Interest: The authors have no conflict of interest to declare.

\section{References}

1. Winkler, W.; Nahvi, A.; Breaker, R.R. Thiamine derivatives bind messenger RNAs directly to regulate bacterial gene ex-pression. Nature 2002, 419, 952-956. [CrossRef] [PubMed]

2. Mandal, M.; Boese, B.; E Barrick, J.; Winkler, W.C.; Breaker, R.R. Riboswitches Control Fundamental Biochemical Pathways in Bacillus subtilis and Other Bacteria. Cell 2003, 113, 577-586. [CrossRef] 
3. Breaker, R.R. Riboswitches and the RNA World. Cold Spring Harb. Perspect. Biol. 2010, 4, a003566. [CrossRef]

4. Serganov, A.; Nudler, E. A Decade of Riboswitches. Cell 2013, 152, 17-24. [CrossRef] [PubMed]

5. McCown, P.J.; Corbino, K.A.; Stav, S.; Sherlock, M.E.; Breaker, R.R. Riboswitch diversity and distribution. RNA 2017, $23,995-1011$. [CrossRef] [PubMed]

6. Mandal, M.; Lee, M.; Barrick, J.E.; Weinberg, Z.; Emilsson, G.M.; Ruzzo, W.L.; Breaker, R.R. A glycine-dependent ri-boswitch that uses cooperative binding to control gene expression. Science 2004, 306, 275-279. [CrossRef] [PubMed]

7. Rodionov, D.A.; Vitreschak, A.G.; Mironov, A.A.; Gelfand, M.S. Regulation of lysine biosynthesis and transport genes in bacteria: Yet another RNA riboswitch? Nucleic Acids Res. 2003, 31, 6748-6757. [CrossRef] [PubMed]

8. Batey, R.T.; Gilbert, S.D.; Montange, R.K. Structure of a natural guanine-responsive riboswitch complexed with the me-tabolite hypoxanthine. Nature 2004, 432, 411-415. [CrossRef]

9. Ames, T.D.; Rodionov, D.A.; Weinberg, Z.; Breaker, R.R. A eubacterial riboswitch class that senses the coenzyme tetrahy-drofolate. Chem. Biol. 2010, 17, 681-685. [CrossRef] [PubMed]

10. Sudarsan, N.; Lee, E.R.; Weinberg, Z.; Moy, R.H.; Kim, J.N.; Link, K.H.; Breaker, R.R. Riboswitches in Eubacteria Sense the Second Messenger Cyclic Di-GMP. Science 2008, 321, 411-413. [CrossRef]

11. Montange, R.K.; Batey, R.T. Riboswitches: Emerging Themes in RNA Structure and Function. Annu. Rev. Biophys. 2008, 37, 117-133. [CrossRef] [PubMed]

12. Sherwood, A.V.; Henkin, T.M. Riboswitch-Mediated Gene Regulation: Novel RNA Architectures Dictate Gene Expression Responses. Annu. Rev. Microbiol. 2016, 70, 361-374. [CrossRef] [PubMed]

13. Grundy, F.J.; Henkin, T.M. The S box regulon: A new global transcription termination control system for methionine and cysteine biosynthesis genes in Gram-positive bacteria. Mol. Microbiol. 1998, 30, 737-749. [CrossRef]

14. McDaniel, B.A.; Grundy, F.J.; Henkin, T.M. A tertiary structural element in S box leader RNAs is required for Sadenosylmethionine-directed transcription termination. Mol. Microbiol. 2005, 57, 1008-1021. [CrossRef] [PubMed]

15. Green, N.J.; Grundy, F.J.; Henkin, T.M. The T box mechanism: tRNA as a regulatory molecule. FEBS Lett. 2009, 584, 318-324. [CrossRef] [PubMed]

16. Kreuzer, K.D.; Henkin, T.M. The T-Box Riboswitch: tRNA as an effector to modulate gene regulation. Microbiol. Spectr. 2018, 6. [CrossRef]

17. Grundy, F.J.; Rollins, S.M.; Henkin, T.M. Interaction between the acceptor end of tRNA and the T box stimulates antiter-mination in the Bacillus subtilis tyrS gene: A new role for the discriminator base. J. Bacterial. 1994, 176, 4518-4526. [CrossRef]

18. Chopin, A.; Biaudet, V.; Ehrlich, S.D. Analysis of the Bacillus subtilis genome sequence reveals nine new T-box leaders. Mol. Microbiol. 1998, 29, 662-664. [CrossRef] [PubMed]

19. Gutiérrez-Preciado, A.; Henkin, T.M.; Grundy, F.J.; Yanofsky, C.; Merino, E. Biochemical features and functional implica-tions of the RNA-based T-box regulatory mechanism. Microbiol. Mol. Biol. Rev. 2009, 73, 36-61. [CrossRef] [PubMed]

20. Weaver, J.W.; Serganov, A. T-box RNA gets boxed. Nat. Struct. Mol. Biol. 2019, 26, 1081-1083. [CrossRef]

21. Zhang, J. Unboxing the T-box riboswitches-A glimpse into multivalent and multimodal RNA-RNA interactions. Wiley In-terdiscip. Rev. RNA 2020, 11. [CrossRef] [PubMed]

22. Henkin, T.M.; Glass, B.L.; Grundy, F.J. Analysis of the Bacillus subtilis tyrS gene: Conservation of a regulatory sequence in multiple tRNA synthetase genes. J. Bacteriol. 1992, 174, 1299-1306. [CrossRef] [PubMed]

23. Grigg, J.C.; Ke, A. Structural Determinants for Geometry and Information Decoding of tRNA by T Box Leader RNA. Struct. 2013, 21, 2025-2032. [CrossRef]

24. Klein, D.; Schmeing, T.; Moore, P.; Steitz, T. The kink-turn: A new RNA secondary structure motif. In The Excitement of Discovery: Selected Papers of Alexander Rich; World Scientific Publishing: Singapore, 2020; Volume 20, pp. 517-524. [CrossRef]

25. Zhang, J.; Ferré-D'Amaré, A.R. Co-crystal structure of a T-box riboswitch stem I domain in complex with its cognate tRNA. Nat. Cell Biol. 2013, 500, 363-366. [CrossRef]

26. Grundy, F.J.; Winkler, W.C.; Henkin, T.M. tRNA-mediated transcription antitermination in vitro: Codon-anticodon pairing independent of the ribosome. Proc. Natl. Acad. Sci. USA 2002, 99, 11121-11126. [CrossRef] [PubMed]

27. Haitani, Y.; Awano, N.; Yamazaki, M.; Wada, M.; Nakamori, S.; Takagi, H. Functional analysis of 1-serineO-acetyltransferase fromCorynebacterium glutamicum. FEMS Microbiol. Lett. 2006, 255, 156-163. [CrossRef]

28. Netzer, R.; Peters-Wendisch, P.; Eggeling, L.; Sahm, H. Cometabolism of a Nongrowth Substrate: L-Serine Utilization by Corynebacterium glutamicum. Appl. Environ. Microbiol. 2004, 70, 7148-7155. [CrossRef] [PubMed]

29. Locasale, J.W. Serine, glycine and one-carbon units: Cancer metabolism in full circle. Nat. Rev. Cancer 2013, 13, 572-583. [CrossRef]

30. Schaechter, M. Escherichia coli and Salmonella 2000: The view from here. Microbiol. Mol. Biol. Rev. 2001, 65, 119-130. [CrossRef] [PubMed]

31. Zhang, Y.; Shang, X.; Lai, S.; Zhang, Y.; Hu, Q.; Chai, X.; Wang, B.; Liu, S.; Wen, T. Reprogramming one-carbon metabolic pathways to decouple L-Serine catabolism from cell growth in Corynebacterium glutamicum. ACS Synth. Biol. 2018, 7, 635-646. [CrossRef] [PubMed]

32. Mundhada, H.; Schneider, K.; Christensen, H.B.; Nielsen, A.T. Engineering of high yield production of L-serine in Esche-richia coli. Biotechnol. Bioeng. 2016, 113, 807-816. [CrossRef] [PubMed]

33. Hama, H.; Sumita, Y.; Kakutani, Y.; Tsuda, M.; Tsuchiya, T. Target of serine inhibition in Escherichia coli. Biochem. Biophys. Res. Commun. 1990, 168, 1211-1216. [CrossRef] 
34. Sun, E.I.; Leyn, S.A.; Kazanov, M.D.; Saier, M.J.; Novichkov, P.S.; Rodionov, D.A. Comparative genomics of metabolic ca-pacities of regulons controlled by cis-regulatory RNA motifs in bacteria. BMC Genomics 2013, 14, 597. [CrossRef] [PubMed]

35. Sonenshein, A.L. Control of key metabolic intersections in Bacillus subtilis. Nat. Rev. Genet. 2007, 5, 917-927. [CrossRef] [PubMed]

36. Zuker, M. Mfold web server for nucleic acid folding and hybridization prediction. Nucleic Acids Res. 2003, 31, 3406-3415. [CrossRef] [PubMed]

37. Marchand, J.A.; Pierson Smela, M.D.; Jordan, T.H.H.; Narasimhan, K.; Church, G.M. TBDB: A database of structurally an-notated T-box riboswitch: tRNA pairs. Nucleic Acids Res. 2020, 49, D229-D235. [CrossRef]

38. Klewing, A.; Koo, B.M.; Krüger, L.; Poehlein, A.; Reuß, D.; Daniel, R.; Gross, C.A.; Stülke, J. Resistance to serine in Bacillus subtilis: Identification of the serine transporter $\mathrm{YbeC}$ and of a metabolic network that links serine and threonine metabo-lism. Environ. Microbiol. 2020, 22, 3937-3949. [CrossRef] [PubMed]

39. Hartmann, A.; Fu, H.A.; Burris, R.H. Influence of amino acids on nitrogen fixation ability and growth of Azospirillum spp. Appl. Environ. Microbiol. 1988, 54, 87-93. [CrossRef]

40. Wang, L.; Zhang, L.; Liu, Z.; Zhao, D.; Liu, X.; Zhang, B.; Xie, J.; Hong, Y.; Li, P.; Chen, S.; et al. A minimal nitro-gen fixation gene cluster from Paenibacillus sp. WLY78 enables expression of active nitrogenase in Escherichia coli. PLoS Genet. 2013, 9, e1003865. [CrossRef]

41. Koo, B.; Kritikos, G.; Farelli, J.D.; Todor, H.; Tong, K.; Kimsey, H.; Wapinski, I.; Galardini, M.; Cabal, A.; Peters, J.M.; et al. Construction and analysis of two genome-scale deletion librar-ies for Bacillus subtilis. Cell Syst. 2017, 4, 291-305. [CrossRef] 